\title{
artigo
}

Grilo, A.P.S.; Maruxo, H.B.; Marques, M.V.; Victoriano, M.A.; Maciel-Júnior, W.

Folder informativo sobre COVID-19 uma estratégia para educação em saúde: revisão de literatura

\section{Folder informativo sobre COVID-19 uma estratégia para educação em saúde: revisão de literatura}

\author{
Informative folder on COVID-19 a strategy for health education: literature review
}

Folder informativo sobre COVID-19 una estrategia de educación en salud: revisión de la literatura

\begin{abstract}
RESUMO
A pandemia COVID-19, tornou-se um grave problema de saúde pública, e dentre as medidas sanitárias propostas estão as de disseminação de conhecimentos para prevenção da doença. Folder é uma estratégia e uma metodologia de ensino, que pode ser utilizado por enfermeiros para ensinar, conscientizar e transformar comportamentos da população. Trata-se de uma revisão integrativa e bibliográfica da literatura, com uso da estratégia PICO, com objetivo de identificar e descrever as principais características para se criar um folder sobre o Covid 19, para o processo de educação. A utilização de folders informativos pelos enfermeiros é de grande auxílio no processo de educação em saúde, fornece melhor compreensão e esclarecimento do assunto, e deve conter informações claras, concisas e de fontes confiáveis a respeito da doença, sendo planejado e criado de acordo com as características do público que será atingido.
\end{abstract}

DESCRITORES: Educação em saúde; Prevenção; Promoção em saúde e Corona vírus.

\section{ABSTRACT}

The COVID-19 pandemic has become a serious public health problem, and among the proposed sanitary measures are the dissemination of knowledge to prevent the disease. Folder is a teaching strategy and methodology, which can be used by nurses to teach, raise awareness and transform the behavior of the population. It is an integrative and bibliographic review of the literature, using the PICO strategy, in order to identify and describe the main characteristics to create a folder on Covid 19, for the education process. The use of informational folders by nurses is of great help in the health education process, provides better understanding and clarification of the subject, and must contain clear, concise and reliable information about the disease, being planned and created in accordance with the guidelines. characteristics of the audience that will be reached.

DESCRIPTORS: Health education; Prevention; Health promotion and Corona virus.

\section{RESUMEN}

La pandemia de COVID-19 se ha convertido en un grave problema de salud pública, y entre las medidas sanitarias propuestas se encuentra la difusión de conocimientos para la prevención de enfermedades. Folder es una estrategia y metodología de enseñanza, que puede ser utilizada por enfermeras para enseñar, sensibilizar y transformar el comportamiento de la población. Es una revisión integrativa y bibliográfica de la literatura, utilizando la estrategia PICO, con el fin de identificar y describir las principales características para crear una carpeta sobre Covid 19, para el proceso educativo. El uso de carpetas informativas por parte del personal de enfermería es de gran ayuda en el proceso de educación en salud, brinda un mejor entendimiento y aclaración del tema, y debe contener información clara, concisa y confiable sobre la enfermedad, siendo planificada y elaborada de acuerdo con las directrices. de la audiencia a la que se llegará.

DESCRIPTORES: Educación para la salud; Prevención; Promoción de la salud y virus Corona.

RECEBIDO EM: 15/01/2021 APROVADO EM: 05/02/2021

\section{Adriana Pereira da Silva Grilo}

Professora do Curso de Enfermagem (UNICID), Mestre em Ciências pela Universidade Universo Veritas (UNIVERITAS - UNG), Doutoranda pela Universidade Universo Veritas (UNIVERITAS - UNG), Especialista em Docência para Ensino Superior, Graduada em Enfermagem pela Universidade Brasil.

ORCID: 0000-0002-1618-4647 


\section{Harriet Bárbara Maruxo}

Enfermeira. Docente em enfermagem pela Universidade Cidade de São Paulo (UNICID). Mestre em ciências da saúde pela Escola de Enfermagem da Universidade de São Paulo (EEUSP).

ORCID: 0000-0002-2405-8640

\section{Marceli Vituri Marques}

Mestre em educação pela Universidade Cidade de São Paulo (UNICID- SP), Especialista em docência, administração hospitalar e ferramentas virtuais, graduada em Enfermagem pelo Centro Universitário São Camilo e docente a graduação na UNICID e pós graduação em cursos no PERU.

ORCID: 0000-0002-4378-287X

\section{Mariana Avendanha Victoriano}

Enfermeira, Professora e Diretora Pedagógica. Mestre em Enfermagem pela Escola de Enfermagem da UFMG na linha "Cuidar em Saúde e em Enfermagem". Membro do Núcleo de Estudos e Pesquisas em Enfermagem Baseada em Evidências - NEPEBE. Pós - Graduanda em "Gestão Escolar Integradora (administração, orientação, inspeção e supervisão)".

ORCID: 0000-0003-3123-9084

\section{Walter Maciel Júnior}

Especialista em oncologia pelo instituto de Ensino e Pesquisa do hospital Israelita Albert Einstein (Einstein-SP), graduado em Enfermagem pela Universidade FUMEC (FUMEC- BH), graduado em publicidade e propaganda pela Universidade FUMEC (FUMEC- BH) docente.

ORCID: 0000-0002-9637-6584

\section{INTRODUÇÃO}

A pandemia da COVID-19, tornou-se um grave problema de saúde pública, e dentre as medidas sanitárias propostas estão as de disseminação de conhecimentos para prevenção da doença.

Como se sabe, a referida patologia é ocasionada por um tipo de Coronavírus, conhecido como SARS-COV-2, cuja primeira ocorrência data de trinta e um de dezembro do ano de dois mil e dezenove, na província de Wuhan na China. No Brasil o primeiro caso, de acordo com dados do Ministério da Saúde, refere-se ao mês de fevereiro de 2020. Desde então, o número de pessoas infectadas e óbitos vem aumentando gradativamente. ${ }^{1 ; 2}$

$\mathrm{O}$ vírus recebe este nome, por ser composto de estruturas que lembram uma coroa e de acordo com a Organização Mundial de Saúde (OMS), os tipos mais prevalentes são o Alpha Corona Vírus 229E e NL63 e o Beta Corona Vírus OC43 e HKU, passíveis de novas mutações. ${ }^{1,2}$

A COVID-19 apresenta diversas manifestações, com destaque para aquelas associadas a infecções respiratórias, dos quais cerca de $80 \%$ podem ser assintomáticos, $20 \%$ necessitar de atendimento hospitalar
A pandemia da COVID-19,

tornou-se um grave problema de saúde pública, e dentre as medidas sanitárias propostas estão as de disseminação de conhecimentos para prevenção da doença. e $5 \%$ de tratamento intensivo. ${ }^{3}$

Estudos científicos, ainda estão sendo desenvolvidos para descrever sua correta fisiopatologia, mas o que se sabe é que seu principal meio de transmissão é por gotículas que ficam dispersas no ar e em superfícies, e que ao entrarem em contato com mucosas chegam ao sistema respiratório, quando então o indivíduo desenvolve os primeiros sintomas mais comuns como: tosse seca, dor de garganta, perda de olfato e paladar, febre, coriza, fadiga entre outros. ${ }^{4,5}$

Pensando-se então na gravidade da atual pandemia, torna-se necessário e imprescindível, o conhecimento e sensibilização da doença para toda a população, visando evitar ou interromper a propagação de fake news, ampliando e conscientizando a todos sobre formas de transmissão e meios de prevenção da COVID-19.

Nesse aspecto, o Enfermeiro como parte da equipe multiprofissional e em consonância com a Lei 7.498/1986, que regulamenta o exercício de Enfermagem, deverá participar e promover ações de educação em saúde, visando a melhoria da saúde populacional, sendo esta essencial nos tempos atuais, a qual vivemos uma grave pandemia. ${ }^{6}$

Por conseguinte, a Educação em saúde 
torna-se uma aliada, na qual seu grande objetivo refere-se a aprimorar o indivíduo e comunidade, em relação às práticas de saúde, informando e orientando. Destaca-se, porém, que a Educação em Saúde, não deve ser desenvolvida visando o condicionamento do indivíduo e a repetição de ações, mas sim sua sensibilização e análise crítica-reflexiva, com vistas a promover a disseminação de informações pautadas em ações científicas. ${ }^{7-8}$

O sucesso das ações de Educação em Saúde encontra-se atrelados as estratégias utilizadas pelos enfermeiros, devendo estas serem simples, diretas e acessíveis ao público-alvo. Entre tantas estratégias que podem ser utilizadas, cita-se o Folder que consiste em um termo em inglês, cujo significado remete a folheto ou brochura, caracterizando-se por uma espécie de documento escrito. $^{7}$

Na criação de um Folder, o Enfermeiro, deve pensar criticamente frente as atuais situações de saúde e doença considerando-se o perfil do leitor e propósito da ação, com vistas a transformação da realidade populacional, no que concerne à saúde. ${ }^{3}$

Para tanto, o Enfermeiro deve considerar ainda o chamado saber popular, que se trata daquele desenvolvido no dia a dia pelas experiências do indivíduo, e que embora falte talvez dados científicos, tem sua validez e importância.; ${ }^{7: 8}$

Assim, ao se utilizar como estratégia o folder informativo, é necessário sensibilidade a ponto de conectar tanto o saber técnico, que se baseia em evidências cientificas, como o saber popular, devendo o Enfermeiro ter claro para si, que tais saberes se confrontam e se completam, sendo o saber popular o ponto de partida, que se associa ao saber técnico-científico, e possibilita a construção de um processo educativo transformador.

Apesar do folder ser um instrumento material físico, torna-se importante agregar a sua entrega metodologias de ensino-aprendizagem participativas e dialógicas, que adequadas às necessidades de saúde individuais e coletivas, atinjam os objetivos propostos numa perspectivada de equidade e da integralidade. ${ }^{8}$
Nesse panorama, em decorrência da pandemia, diversos foram os cenários enfrentados no Brasil, que se deparou com uma constante elevação do número de casos, óbitos, ocupações nos leitos de unidades de terapia intensiva, segunda onda e mais atualmente falta de oxigênio.

Pensando-se então em atender as medidas sanitárias da OMS e do Ministério da Saúde, frente a pandemia da COVID-19, realizou-se este trabalho voltado a utilização de um folder ilustrativo para a educação em saúde da referida patologia, como estratégia de sensibilização a população acerca dos conhecimentos e cuidados que potencializem o controle da situação pandêmica.

Assim, estre trabalho tem por objetivo identificar e descrever as principais características necessárias para a criação de um folder com informações sobre a COVID-19, voltado ao processo de educação em saúde, como ferramenta utilizada por enfermeiros, em consonância com evidências científicas atuais.

\section{MÉTODO}

O presente estudo trata-se de uma revisão integrativa de literatura que, tem como finalidade agrupar e integrar estudos referentes a um determinado assunto. A revisão integrativa proporciona a síntese das informações e a incorporação do uso de resultados de estudos significativos na prática, sendo muito utilizada na área da saúde. ${ }^{9}$

O desenvolvimento desta revisão foi realizado por meio de fases, sendo estas: a elaboração da pergunta norteadora, a busca bibliográfica na literatura, a tabulação dos dados, a análise crítica dos estudos, a discussão dos resultados e a estruturação final da revisão integrativa com sua apresentação.

Nesta revisão, contou-se com a estratégia PICO, que se configura como um acrônimo no qual $\mathrm{P}$ significa paciente ou população; I trata da intervenção, C refere-se à comparação e $\mathrm{O}$ remete ao desfecho. $\mathrm{O}$ uso de tal estratégia, auxilia na elaboração da pergunta de pesquisa, con- tribuindo para que esta seja forte e nos remeta a uma consistente recuperação de estudos nas bases de dados. ${ }^{10}$

Dessa forma, a pergunta norteadora utilizada foi: Quais as principais características que um folder informativo sobre COVID-19, voltado a população leiga, deve apresentar para se realizar uma ação educativa em saúde na atenção básica? No qual, $\mathrm{P}$ trata da população leiga, I envolve compreender as informações necessárias sobre COVID-19 que um folder deve conter e $\mathrm{O}$ inclui a ação educativa na atenção básica. É necessário destacar, que de acordo com o tipo e a forma como a revisão é realizada, não há necessidade de se utilizar todos os recursos da estratégia $\mathrm{PICO}$, de forma que nesta revisão não se utilizou o $\mathrm{C}$ que se refere a comparação.

Os estudos foram selecionados por meio de buscas nas bases de dados eletrônicas Scientific Electronic Library Online (Scielo), Literatura Latino-Americana e do Caribe em Clínicas de Saúde (Lilacs) e portal de pesquisa da Biblioteca Nacional de Medicina dos Estados Unidos da América (PubMed).

Visando enriquecer esta pesquisa, e pensando na complexidade de informações referentes a COVID-19, optou-se por incluir como fonte de dados, as informações provenientes de órgãos nacionais referências para a área da saúde, responsáveis em promover, prevenir e controlar a saúde frente a Pandemia, como o Ministério da Saúde e recomendações oficiais dos órgãos de classe da profissão de enfermagem no Brasil, citando-se o Conselho Federal de Enfermagem (COFEN) e o Conselho Regional de Enfermagem de São Paulo (COREN-SP).

Para a busca do conteúdo analisado utilizou-se os seguintes descritores Educação em saúde; Prevenção; Promoção em saúde e COVID-19, selecionados por meio dos vocabulários das bases da Biblioteca Virtual em Saúde (BVS) através dos Descritores em Ciências da Saúde da Bireme (Decs). Associado aos descritores, utilizou-se também a palavra-chave Folder. Os descritores foram combinados entre si por meio do operador booleano and. 
Como critérios inclusão, optou-se por artigos publicados exclusivamente no idioma português, cujos textos estivessem disponíveis na íntegra e de forma gratuita, nas bases de dados citadas anteriormente, no período de 2004 a 2020 e que respondessem a pergunta de pesquisa.

Excluiu-se os estudos cujo acesso era pago e sem disponibilidade na íntegra, em idioma diferente do português, fora do período de tempo estabelecido ou ainda que não respondesse a pergunta de pesquisa e ao objetivo deste trabalho, além daqueles repetidos.
Os estudos foram analisados inicialmente apenas pela leitura do título, sendo excluídos aqueles que os autores considerassem que não se relacionavam ao assunto. Após essa primeira análise, seguiu-se a leitura dos resumos, os quais outros artigos foram excluídos. Findada a leitura dos resumos, evoluiu-se para a última etapa de seleção que tratou da leitura na íntegra dos artigos, possibilitando sua inclusão ou exclusão, conforme temática central.

Os artigos inclusos neste estudo, foram analisados por instrumento construído

\section{Figura 1. Estratégia de busca dos estudos constituintes da amostra}

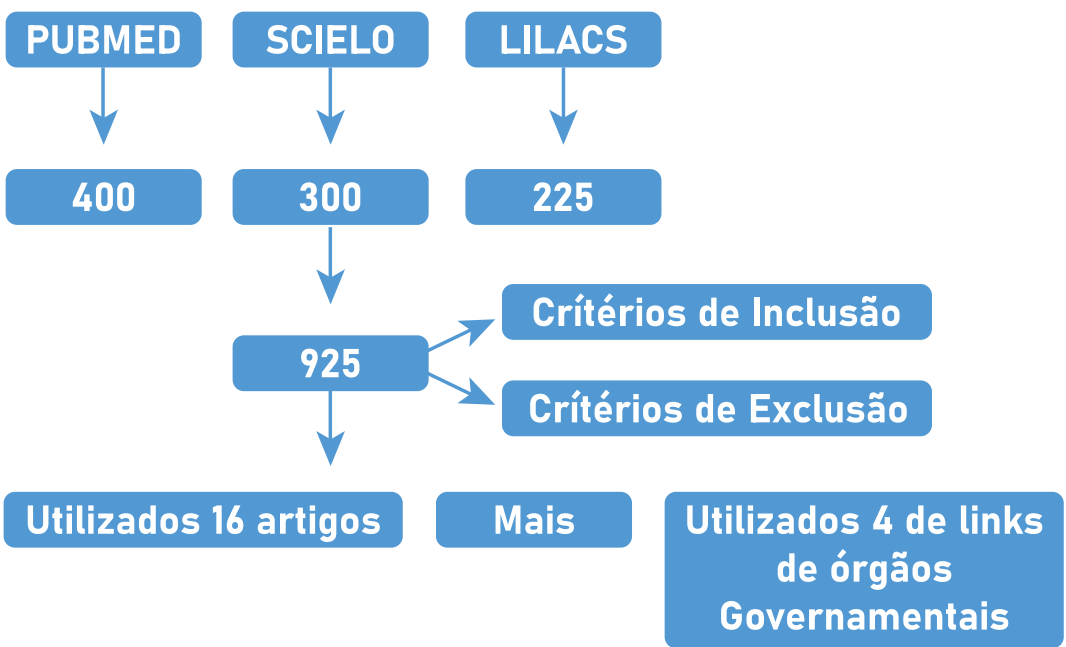

Fonte: Autores, São Paulo, 2021

\begin{tabular}{|c|c|c|}
\hline \multicolumn{3}{|c|}{ Quadro 1- Ano de publicação dos artigos analisados, São Paulo 2021. } \\
\hline ANO: & QUANTIDADE: & PORCENTAGEM: \\
\hline 2004 & 01 & $5 \%$ \\
\hline 2007 & 01 & $5 \%$ \\
\hline 2009 & 01 & $5 \%$ \\
\hline 2010 & 01 & $5 \%$ \\
\hline 2011 & 02 & $10 \%$ \\
\hline 2012 & 01 & $5 \%$ \\
\hline 2013 & 02 & $10 \%$ \\
\hline 2014 & 02 & $10 \%$ \\
\hline 2019 & 01 & $5 \%$ \\
\hline 2020 & 08 & $40 \%$ \\
\hline TOTAL & 20 & $100 \%$ \\
\hline Fonte: Autores, 2021. & & \\
\hline
\end{tabular}

pelos próprios autores, verificando-se base de dados, ano, tema central e tipo de estudo. A busca ocorreu entre os meses de setembro a novembro de 2020 , sendo os dados obtidos analisados por estatística simples e apresentados por meio de quadros, figuras e análise descritiva.

\section{RESULTADOS}

Foram encontrados um total de 925 artigos, que após a aplicação dos critérios de inclusão e exclusão, análise dos títulos, resumos e leitura na íntegra, selecionou-se 16 estudos que atenderam aos critérios de elegibilidade, porém, na busca por informações oficiais sobre a COVID-19, acrescentou-se a esses estudos 4 referencias provenientes dos órgãos governamentais brasileiros e entidades de classe, de forma que a amostra final deste estudo foi formada por 20 (100\%) trabalhos, conforme visualiza-se na figura 1.

Entre os estudos que compuseram a amostra, 09 artigos (45\%) foram publicados no Lilacs, 06 (30\%) no Scielo, 02 (10\%) no Ministério da Saúde, 01 (5\%) na Pubmed, 01 (5\%) no COREN/COFEN e 01 na Secretaria de Saúde do Estado de São Paulo.

Em relação ao ano de publicação, estes variaram entre 2004 e 2020, apresentando um maior índice de publicações no ano de 2020, como já esperado, devido este ser o ano em que a pandemia se instalou, havendo necessidade de alta produção científica sobre a referida temática, visando a capacitação profissional. A distribuição dos anos de publicação pode ser vista no Quadro 1.

Já no que concerne ao tipo de estudo, verificou-se que 09 (45\%) tratava-se de Revisões de Literatura, sendo estas narrativas, integrativas e ou sistemáticas; 04 (20\%) referiam-se a estudos descritivos, 03 (15\%) a informativos bibliográficos, 02 (10\%) eram estudos quantitativos e 02 (10\%) relatos de experiência.

Como se sabe, as revisões de literatura são amplamente utilizadas quando pensamos na prática baseada em evidências, visto que estas podem esgotar a literatura 


\section{artigo}

Grilo, A.P.S.; Maruxo, H.B.; Marques, M.V.; Victoriano, M.A.; Maciel-Júnior, W.

Folder informativo sobre COVID-19 uma estratégia para educação em saúde: revisão de literatura

cientifica com publicações de um determinado período, extraindo destes seus principais resultados e assim compartilhando com o público em geral, visando solucionar uma questão e ou problema anteriormente elencado.

Dessa forma, quando falamos de um assunto tão atual como a COVID-19, aliado a temática de educação em saúde por meio do desenvolvimento de um Folder, as revisões proporcionam melhores evidências cientificas para o aprimoramento do público em geral.

Em relação a temática central dos estudos, encontramos que 10 (50\%) artigos referiam-se à Educação em Saúde, abordando ações voltadas a promoção da saúde, 06 (30\%) tratavam da COVID-19 destacando sintomatologia, transmissibilidades, mecanismos e equipamentos para a prevenção e $04(20 \%)$ trouxeram ações relacionadas a utilização de folders e folhetos informativos para a população com diferentes patologias. O Quadro 2, apresenta o resumo dos estudos utilizados.

Em se tratando da utilização do Folder, evidenciamos que este é utilizado

Quadro 2 - Resumo dos estudos utilizados

\begin{tabular}{|c|c|c|c|c|}
\hline $\begin{array}{l}\text { AUTORIA E ANO DE } \\
\text { PUBLICAÇÃO }\end{array}$ & TítULO & BASE DE DADOS & METODOLOGIA & IDEIA PRINCIPAL DO ARTIGO \\
\hline Ministério da Saúde & & & & O Caderno de Educação Popular e Saúde \\
\hline $\begin{array}{l}\text { Ano de publicação } \\
2007\end{array}$ & $\begin{array}{c}\text { Caderno de educação Popu- } \\
\text { lar em Saúde }\end{array}$ & $\begin{array}{l}\text { Link do } \\
\text { Ministério da } \\
\text { Saúde }\end{array}$ & $\begin{array}{l}\text { Bibliográfico/ } \\
\text { informativo }\end{array}$ & $\begin{array}{l}\text { apresenta um rico material para reflexão, } \\
\text { conhecimento e formação, pondo em } \\
\text { diálogo significativas experiências de } \\
\text { educação popular em saúde vivenciadas } \\
\text { por múltiplos atores sociais. }\end{array}$ \\
\hline $\begin{array}{l}\text { Entidades de classe } \\
\text { COREN e COFEN }\end{array}$ & \multirow{2}{*}{$\begin{array}{l}\text { COVID-19: Orientações } \\
\text { sobre a colocação e retira- } \\
\text { das dos equipamentos de } \\
\text { proteção individual (EPIs). }\end{array}$} & \multirow{2}{*}{ Link do COREN } & \multirow{2}{*}{$\begin{array}{l}\text { Bibliográfico/ } \\
\text { informativo }\end{array}$} & \multirow{2}{*}{$\begin{array}{l}\text { Orientação de sequência de colocação e } \\
\text { retirada dos equipamentos de proteção } \\
\text { individual (EPIs). }\end{array}$} \\
\hline $\begin{array}{l}\text { Ano de publicação } \\
2020\end{array}$ & & & & \\
\hline $\begin{array}{c}\text { Secretária de Estado } \\
\text { de Saúde }\end{array}$ & \multirow{2}{*}{$\begin{array}{l}\text { Plano de contingência para } \\
\text { epidemia da doença pela } \\
\text { COVID-19 }\end{array}$} & \multirow[b]{2}{*}{$\begin{array}{l}\text { Link da Secretá- } \\
\text { ria do Estado }\end{array}$} & \multirow[b]{2}{*}{$\begin{array}{l}\text { Bibliográfico/ } \\
\text { informativo }\end{array}$} & \multirow{2}{*}{$\begin{array}{l}\text { A ideia principal e informar os primei- } \\
\text { ros planos de ação para combater a } \\
\text { pandemia, explicando para a população a } \\
\text { importância das medidas tomadas para } \\
\text { o combate da doença, demonstrando a } \\
\text { importância da quarentena. }\end{array}$} \\
\hline $\begin{array}{l}\text { Ano de publicação } \\
2020\end{array}$ & & & & \\
\hline Ministério da Saúde & \multirow[b]{2}{*}{$\begin{array}{l}\text { "Tem dúvidas sobre a co- } \\
\text { rona vírus? O Ministério da } \\
\text { Saúde te responde!" }\end{array}$} & \multirow[b]{2}{*}{$\begin{array}{l}\text { Link do Ministé- } \\
\text { rio da Saúde }\end{array}$} & \multirow[b]{2}{*}{$\begin{array}{l}\text { Cartilha Revisão } \\
\text { Sistemática }\end{array}$} & \multirow{2}{*}{$\begin{array}{l}\text { A ideia principal do artigo é responder dúvidas } \\
\text { comuns da população e informar, explicando } \\
\text { como é transmitido, sintomas, como realizar } \\
\text { o isolamento social, grupo de risco, relação } \\
\text { com gripe e a vacina de gripe, instruções sobre } \\
\text { produção e uso de máscara. }\end{array}$} \\
\hline $\begin{array}{l}\text { Ano de publicação } \\
2020\end{array}$ & & & & \\
\hline $\begin{array}{l}\text { Russo MRR, Merce- } \\
\text { des R, Baltazar MM } \\
\text { et al. }\end{array}$ & \multirow{2}{*}{$\begin{array}{l}\text { Epidemiologia, políticas } \\
\text { públicas e pandemia de } \\
\text { Covid-19: o que esperar no } \\
\text { Brasil }\end{array}$} & \multirow[t]{2}{*}{ SCIELO } & \multirow[t]{2}{*}{$\begin{array}{c}\text { Revisão } \\
\text { bibliográfica e } \\
\text { integrativa }\end{array}$} & \multirow{2}{*}{$\begin{array}{c}\text { Discutir as experiências e contradições } \\
\text { no controle da pandemia de Covid-19 } \\
\text { sob a perspectiva da epidemiologia e das } \\
\text { políticas públicas brasileiras. }\end{array}$} \\
\hline Publicado em 2020 & & & & \\
\hline $\begin{array}{c}\text { Freitas A.R.R; Napi- } \\
\text { monga M; Donalisio } \\
\text { M.R }\end{array}$ & \multirow{2}{*}{$\begin{array}{l}\text { Análise da gravidade de } \\
\text { COVID-19. }\end{array}$} & \multirow{2}{*}{ SCIELO } & \multirow{2}{*}{$\begin{array}{c}\text { Revisão } \\
\text { bibliográfica e } \\
\text { integrativa }\end{array}$} & \multirow{2}{*}{$\begin{array}{c}\text { Análise dos casos de COVID19 Apresen- } \\
\text { tação de indicadores de transmissibilida- } \\
\text { de e gravidade da pandemia de COVID-19 } \\
\text { em diferentes regiões, mostra também, } \\
\text { comparações entre outras doenças seve- } \\
\text { ras da história. }\end{array}$} \\
\hline Publicado em 2020 & & & & \\
\hline $\begin{array}{l}\text { Falkenberg, Mirian } \\
\text { Benites et al. }\end{array}$ & \multirow[b]{2}{*}{$\begin{array}{l}\text { Educação em saúde e edu- } \\
\text { cação na saúde: conceitos } \\
\text { e implicações para a saúde } \\
\text { coletiva }\end{array}$} & \multirow[b]{2}{*}{ SCIELO } & \multirow[b]{2}{*}{$\begin{array}{c}\text { Revisão } \\
\text { bibliográfica e } \\
\text { integrativa }\end{array}$} & \multirow{2}{*}{$\begin{array}{l}\text { O presente artigo tem como objetivo } \\
\text { analisar os conceitos-chave relativos à } \\
\text { Educação em Saúde e Educação na Saú- } \\
\text { de e suas interfaces no campo da Saúde } \\
\text { Coletiva. Embora apresentem diferenças, } \\
\text { é frequente na prática dos serviços, a } \\
\text { utilização das diversas variantes a elas } \\
\text { relacionadas de forma indistinta }\end{array}$} \\
\hline Publicado em 2014 & & & & \\
\hline
\end{tabular}




\begin{tabular}{|c|c|c|c|c|}
\hline $\begin{array}{l}\text { Nascimento E.A; } \\
\text { Tarcia R.M.L; Et al. }\end{array}$ & & & & $\begin{array}{l}\text { Estudo com abordagem a pacientes, } \\
\text { familiares e cuidadores, sobre a com- }\end{array}$ \\
\hline Publicado em 2010 & $\begin{array}{l}\text { Folhetos educativos em } \\
\text { Saúde }\end{array}$ & SCIELO & quantitativo & $\begin{array}{c}\text { unidades de saúde, com temas respecti- } \\
\text { vos sobre cuidados domiciliares e dúvidas } \\
\text { sobre diagnósticos, e se eles se sentem } \\
\text { confortáveis a lerem e entenderem os } \\
\text { folhetos entregues. }\end{array}$ \\
\hline $\begin{array}{l}\text { Menezes GAC, Rosa } \\
\text { RSD. }\end{array}$ & \multirow{2}{*}{$\begin{array}{l}\text { Práticas educativas em saú- } \\
\text { de: a enfermagem revendo } \\
\text { conceitos na promoção do } \\
\text { autocuidado }\end{array}$} & \multirow{2}{*}{ LILACS } & \multirow{2}{*}{$\begin{array}{c}\text { Revisão } \\
\text { bibliográfica e } \\
\text { integrativa }\end{array}$} & \multirow{2}{*}{$\begin{array}{c}\text { Estudo com abordagem aos conceitos } \\
\text { de educação em saúde e seus benefi- } \\
\text { cios para a promoção e prevenção de } \\
\text { doenças. }\end{array}$} \\
\hline Publicado em 2004 & & & & \\
\hline $\begin{array}{l}\text { Paula MANR; Carva- } \\
\text { Iho AP }\end{array}$ & \multirow{2}{*}{$\begin{array}{l}\text { O gênero textual folder a } \\
\text { serviço da educação am- } \\
\text { biental. }\end{array}$} & \multirow{2}{*}{ PUBMED } & \multirow{2}{*}{$\begin{array}{l}\text { Revisão } \\
\text { bibliográfica e } \\
\text { integrativa }\end{array}$} & \multirow{2}{*}{$\begin{array}{c}\text { Descrição de conceito, benefícios e carac- } \\
\text { terísticas de folder. }\end{array}$} \\
\hline Publicado em 2014 & & & & \\
\hline Silva P.F; Fleury E.M & \multirow[b]{2}{*}{$\begin{array}{l}\text { Efeitos da apresentação } \\
\text { de material educativo para } \\
\text { pacientes com diabetes } \\
\text { mellitus tipo 2, sobre co- } \\
\text { nhecimento da enfermidade } \\
\text { e a adesão ao tratamento. }\end{array}$} & \multirow[b]{2}{*}{ LILACS } & \multirow[b]{2}{*}{ Quantitativa } & \multirow[b]{2}{*}{$\begin{array}{l}\text { Avaliar junto aos participantes a adequa- } \\
\text { ção do conteúdo da cartilha educativa, } \\
\text { estudo qualitativo em pesquisa na com- } \\
\text { preensão sobre a doença após esclareci- } \\
\text { mento verbal e com material educativo. }\end{array}$} \\
\hline Publicado em 2009. & & & & \\
\hline Cardoso, J. & \multirow[b]{2}{*}{$\begin{array}{l}\text { Entre campanhas, notícias } \\
\text { e direitos: os laços entre } \\
\text { comunicação e SUS numa } \\
\text { trajetória de pesquisa }\end{array}$} & \multirow[b]{2}{*}{ LILACS } & \multirow[b]{2}{*}{$\begin{array}{l}\text { Relato de expe- } \\
\text { riencia }\end{array}$} & \multirow[b]{2}{*}{$\begin{array}{l}\text { Uma trajetória individual que reverbera } \\
\text { em suas práticas e pesquisas, interfaces } \\
\text { da comunicação e da saúde ao longo do } \\
\text { processo de construção do Sistema Único } \\
\text { de Saúde no Brasil. }\end{array}$} \\
\hline Publicado em 2020 & & & & \\
\hline Pereira S. W. & \multirow[b]{2}{*}{$\begin{array}{l}\text { Abordagens metodológicas } \\
\text { utilizadas em intervenções } \\
\text { educativas voltadas a indiví- } \\
\text { duos com diabetes mellitus }\end{array}$} & \multirow[b]{2}{*}{ LILACS } & \multirow[b]{2}{*}{ Revisão narrativa } & \multirow[b]{2}{*}{$\begin{array}{l}\text { O objetivo da presente pesquisa foi } \\
\text { identificar os tipos de abordagens me- } \\
\text { todológicas utilizadas nas intervenções } \\
\text { educativas voltadas para as pessoas que } \\
\text { convivem com Diabetes Mellitus. }\end{array}$} \\
\hline Publicado em 2020 & & & & \\
\hline $\begin{array}{l}\text { Roecker S., Almeida } \\
\text { EFP, Marcon SS }\end{array}$ & \multirow{2}{*}{$\begin{array}{l}\text { O trabalho educativo do } \\
\text { enfermeiro na estratégia } \\
\text { saúde da familia. }\end{array}$} & \multirow[b]{2}{*}{ SCIELO } & \multirow[b]{2}{*}{$\begin{array}{l}\text { Descritivo/ } \\
\text { exploratório }\end{array}$} & \multirow{2}{*}{$\begin{array}{l}\text { Este estudo objetivou identificar a } \\
\text { perspectiva dos enfermeiros quanto à } \\
\text { educação em saúde e averiguar como } \\
\text { esta é concebida, planejada, executada e } \\
\text { avaliada na Estratégia Saúde da Familia }\end{array}$} \\
\hline Publicado em 2013 & & & & \\
\hline $\begin{array}{l}\text { David HM, Scher- } \\
\text { lowski L, Bonetti OP; } \\
\text { Silva, Ferreira MS. }\end{array}$ & \multirow[t]{2}{*}{$\begin{array}{c}\text { Educação Popular em Saúde } \\
\text { como Política do Sistema } \\
\text { único de Saúde. }\end{array}$} & \multirow[t]{2}{*}{ LILACS } & \multirow[t]{2}{*}{$\begin{array}{c}\text { Revisão } \\
\text { bibliográfica e } \\
\text { Documental. }\end{array}$} & \multirow[t]{2}{*}{$\begin{array}{l}\text { Discutir educação Popular em Saúde } \\
\text { como política integrante do SUS. }\end{array}$} \\
\hline Publicado em 2012 & & & & \\
\hline $\begin{array}{l}\text { Freitas FV, Rezende } \\
\text { FLA. }\end{array}$ & \multirow{2}{*}{$\begin{array}{l}\text { Modelos de comunicação } \\
\text { e uso de impressos na } \\
\text { educação em saúde: uma } \\
\text { pesquisa bibliográfica. }\end{array}$} & \multirow[b]{2}{*}{ LILACS } & \multirow[b]{2}{*}{$\begin{array}{c}\text { Revisão } \\
\text { bibliográfica e } \\
\text { Documental. }\end{array}$} & \multirow{2}{*}{$\begin{array}{c}\text { O artigo apresenta os resultados de uma } \\
\text { pesquisa bibliográfica sobre o uso de ma- } \\
\text { teriais impressos na educação em saúde, } \\
\text { enfocando os modelos de comunicação, } \\
\text { as representações dos usuários e as } \\
\text { dinâmicas da seleção de conteúdos e de } \\
\text { avaliação. }\end{array}$} \\
\hline 2011 & & & & \\
\hline
\end{tabular}




\section{artigo}

Grilo, A.P.S.; Maruxo, H.B.; Marques, M.V.; Victoriano, M.A.; Maciel-Júnior, W.

Folder informativo sobre COVID-19 uma estratégia para educação em saúde: revisão de literatura

\begin{tabular}{|c|c|c|c|c|}
\hline $\begin{array}{l}\text { Sibellino LO; Freire } \\
\text { RM et al }\end{array}$ & $\begin{array}{c}\text { Atuação discente na produ- } \\
\text { ção de folders e panfletos } \\
\text { sobre arboviroses como } \\
\text { materiais educativos. }\end{array}$ & LILACS & $\begin{array}{l}\text { Relato de expe- } \\
\text { riência }\end{array}$ & $\begin{array}{l}\text { A construção de instrumentos de divul- } \\
\text { gação no campo da saúde é fundamental } \\
\text { para esclarecer a sociedade acerca de } \\
\text { temas tão relevantes à saúde pública. Os } \\
\text { materiais produzidos pelos alunos ob- } \\
\text { tiveram êxito em abordar esse assunto, } \\
\text { uma vez que apresentaram informações } \\
\text { relevantes sobre as doenças e ilustra- } \\
\text { ções, as quais contribuem para comuni- } \\
\text { cação eficaz com a população em geral, } \\
\text { desde o grupo infanto-juvenil ao idoso. }\end{array}$ \\
\hline $\begin{array}{c}\text { Cervera DPP, Parreira } \\
\text { BDM, Goulart BF }\end{array}$ & $\begin{array}{c}\text { Educação em Saúde: Per- } \\
\text { cepção dos enfermeiros da } \\
\text { Atenção básica em Uberaba } \\
\text { (MG). }\end{array}$ & LILACS & $\begin{array}{l}\text { Descritivo e } \\
\text { Qualitativo. }\end{array}$ & $\begin{array}{c}\text { Conhecer a percepção de enfermeiros, } \\
\text { vinculados à Estratégia Saúde da Fa- } \\
\text { mília, sobre a educação em saúde, em } \\
\text { Uberaba (MG). }\end{array}$ \\
\hline $\begin{array}{l}\text { Machado MF Amuz- } \\
\text { za; Santos AP; et al }\end{array}$ & $\begin{array}{c}\text { A influência da enfermagem } \\
\text { na realização de educação } \\
\text { popular em saúde: revisão } \\
\text { integrativa }\end{array}$ & LILACS & $\begin{array}{l}\text { Descritivo e } \\
\text { Qualitativo. }\end{array}$ & $\begin{array}{c}\text { Analisar as publicações com enfoque em } \\
\text { Educação Popular em Saúde disponiveis } \\
\text { em periódicos indexados na Biblioteca } \\
\text { Virtual da Saúde (BVS), no período de } \\
2007 \text { a } 2012 \text {. }\end{array}$ \\
\hline Lana, R; Martins et al. & $\begin{array}{c}\text { Emergência do novo } \\
\text { coronavírus (SARS-CoV-2) } \\
\text { e o papel de uma vigilância } \\
\text { nacional em saúde oportuna } \\
\text { e efetiva. }\end{array}$ & SCIELO & Descritivo. & $\begin{array}{l}\text { Descreve a potencial chegada do novo } \\
\text { vírus coloca à prova a estrutura de vigi- } \\
\text { lância existente no país, principalmente } \\
\text { num momento em que a redução de in- } \\
\text { vestimentos no Sistema Único de Saúde } \\
\text { (SUS) e na pesquisa fragiliza a capacidade } \\
\text { de detecção precoce e de resposta. }\end{array}$ \\
\hline & & & & \\
\hline
\end{tabular}

como ferramenta de instrução e prevenção, apresentando como pontos positivos para sua implementação: comunicação simples e direta, ilustração efetiva, contextualização verbal satisfatória, entendimento do assunto de modo prático e transparente, e abordagem qualitativa do público-alvo em questão.

Ao analisar os folders informativos criados pelo Ministério da Saúde, pode-se perceber, que os tópicos mais utilizados são: definição, dados epidemiológicos, sinais e sintomas, tratamento, e onde procurar ajuda, por meio de sites, telefones e unidades básicas de saúde. ${ }^{11 ; 12}$

De acordo com o nosso entendimento após a análise das referências utilizadas, al- guns tópicos são essenciais para um folder informativo transmitir uma comunicação educativa efetiva, cujo objetivo é a promoção da saúde e a prevenção de agravos.

No caso deste trabalho, é necessário obter dados científicos e traçar um perfil histórico, fisiopatológico, sintomatologia e medidas de prevenção baseada nas seguintes perguntas: O que é o Covid-19? O que é pandemia? Qual a história do vírus? Tem tratamento? Qual o tratamento? Qual a prevenção?

As orientações também deverão ser voltadas à promoção da saúde física e mental da população. O objetivo é apoiar as estratégias locais para retomada segura das atividades e do convívio social, respeitando as especificidades e características de cada setor ou ramo de atividade. ${ }^{13,14}$

Ao se falar de um texto informativo, entende-se dizer que é algo sobre informação, então deve-se descrever as informações cruciais, visando o entendimento rápido e transparente do assunto. ${ }^{1,7-8}$

Algumas pessoas confundem o folder com o panfleto, embora semelhantes, o folder é um impresso que possui no mínimo uma dobra, utiliza imagens, dá destaque às ideias mais importantes com quadros ou palavras em fontes maiores (maiúsculas, coloridas ou de diferentes formatos). Tem como propósito comunicar rapidamente ideias sem cansar o leitor. O folder é dobrado conforme a sequência 
de argumentos, a capa contém a chamada principal, a qual deve despertar a curiosidade para a abertura dele. $13 ; 14$

Ao abrir a primeira dobra nota-se o detalhamento do que a capa anuncia. A última dobra (externa) é, geralmente, reservada para os dados como endereço, telefone, e-mail e outras informações como distribuidores, representantes, patrocinadores, mapas de localização e outras informações de contato. ${ }^{16 ; 17}$

Deve ser organizado a partir da aproximação com outros sujeitos no espaço comunitário, privilegiando os movimentos sociais locais, num entendimento de saúde como prática social e global e tendo como balizador ético-político os interesses das classes populares. Baseia-se no diálogo com os saberes prévios dos usuários dos serviços de saúde, seus saberes "populares", e na análise crítica da realidade. ${ }^{11}$

Deve-se também considerar o público-alvo que irá receber este material. $\mathrm{O}$ importante é que seja identificada com clareza, bem como a escolha das técnicas pedagógicas e ludo pedagógicas previstas em todas as ações de intervenção. Devem ser redigidos em termos da população-alvo, incluir sempre uma ação que é expressa por um verbo, A ação deve sempre se referir a algum objeto ou conteúdo. ${ }^{3: 16}$

O levantamento de dados epidemiológicos, podem ser estritamente importantes, pois, levantam dados atuais e significativos do problema, sendo evidenciado a evolução, os pontos negativos e positivos, e até mesmo pode ser usado como uma ferramenta de prevenção e promoção, em uma forma de planejamento amplo 2;5,6

Tratando-se de um folder informativo e preventivo, quando se compete na questão de tratamento, é bom destacar-se formas de tratamentos que não envolva medicações ou terapias hospitalares, se possível, pois, a ideia principal, é a prevenção, para não haver a necessidade de uma internação hospitalar, mas lembrando que alguns temas, tem a necessidade imprescindível de intervenção médica hospitalar, abrangendo os fundamentos comuns de um folder informativo, que é, trazer as informações corretas. E lembrar

\section{Deve ser organizado}

a partir da

aproximação com

outros sujeitos no

espaço comunitário,

privilegiando

os movimentos

sociais locais, num

entendimento

de saúde como

prática social e

global e tendo

como balizador

ético-político os

interesses das classes

populares. Baseia-se

no diálogo com os

saberes prévios dos

usuários dos serviços

de saúde, seus

saberes "populares",

e na análise crítica da

realidade. de enumerar e destacar quais os principais sintomas que podem surgir.

Vale relembrar sobre a importância em não só entregar em mãos ou disponibilizar o folder, mas também, estimular a leitura para gerar curiosidades no leitor e até questionamentos. Os enfermeiros deverão estar disponíveis para esclarecimentos e dúvidas.

Em um âmbito hospitalar, quando o folder for destinado a profissionais de saúde, seus objetivos estão voltados para a educação permanente e continuada a fim de promover o conhecimento entendimento, curiosidades, e protocolos institucionais conforme cada instituição. Como por exemplo, se trouxer informações de acordo com as diretrizes do COREN (Conselho Regional de Enfermagem), onde descreve a sequência correta de vestimentas EPIs (equipamentos de proteção individual) de acordo com o protocolo de proteção padrão, com o intuito de orientar a forma correta de seu uso aqueles profissionais que irão trabalhar diretamente com pacientes com suspeitas de COVID-19, ou até em casos confirmados de COVID-19. ${ }^{17 ; 18}$

Conforme a discussão da revista da escola de enfermagem da USP ${ }^{14,17}$, a abordagem efetiva, se deu pela transparência dos conteúdos obtidos nos folders: informações claras, objetivas, de fácil compreensão, sem termos técnicos, imagens ilustrativas, uma fonte legível, tamanho de letra e destaca também, que a explicação verbal acompanhada pelo folheto, se mostrou ainda mais satisfatório no quesito compreensão ${ }^{13}$.

A utilização de folders informativos para os enfermeiros é de grande auxílio no processo de educação em saúde, podendo fornecer melhor compreensão e esclarecimento dos cuidados necessários em qualquer instituição de saúde, seja nível primário, secundário, terciário, alta hospitalar, campanhas, exames, acolhimento, ambulatório etc.

A educação popular em saúde continua sendo hoje um desafio aos gestores e profissionais na busca por práticas integrais, mais voltadas às reais necessidades das populaçôes e considerando, como supor- 
te para essas práticas, tanto processos de informação e comunicação como de participação popular e participação social. Para promover a educação em saúde, também é necessário que ocorra a educação voltada para os profissionais de saúde, e se fala, então, em educação na saúde. ${ }^{11}$

\section{CONCLUSÃO}

Embora muitas instituições de saúde em âmbito nacional utilizem materiais educativos elaborados por seus profissionais ou provenientes de órgãos governamentais, institutos de pesquisa, associações ou outros, há poucos estudos criteriosos de avaliação de resultados. Na maioria das vezes se desconhece o papel que os materiais impressos efetivamente desempenham na comunicação entre profissionais e usuários dos serviços de saúde ${ }^{13}$.
Na maioria das vezes

se desconhece o papel

que os materiais

impressos efetivamente

desempenham na

comunicação entre

profissionais e

usuários dos

serviços de saúde
Para que o informativo alcance a eficácia, é imprescindível que seja baseado em cartilhas estabelecidas pelo Ministério da Saúde, e determinações da OMS (Organização Mundial da Saúde).

De acordo com as referências utilizadas, os principais benefícios em se utilizar um folder como ferramenta de instrução e prevenção são: comunicação simples e direta, ilustração efetiva, contextualização verbal satisfatória, entendimento do assunto de modo prático e transparente, e abordagem qualitativa do público-alvo em questão.

Sugerimos ainda que estudos como estes continuem sendo elaborados, pois o conhecimento e orientação são imprescindíveis para o controle e disseminação de doenças. Para promover a educação em saúde, também é necessário que ocorra a educação voltada para os profissionais de saúde, e se fala, então, em educação na saúde. I

\section{REFERÊNCIAS}

1. Ministério da Saúde. O que é COVID-19. DF: O Ministério; 2020. Acesso em 23 de maio de 2020. Disponível em: https:// coronavirus.saude.gov.br/sobre-a-doenca.

2. Rafael, R, Neto, M, Carvalho, M, David, H., Acioli, S, \& Faria, M. (2020). Epidemiologia, políticas públicas e pandemia de Covid-19: o que esperar no Brasil? [Epidemiology, public policies and Covid-19 pandemics in Brazil: what can we expect?] [Epidemiologia, políticas públicas y la pandémia de Covid-19 en Brasil: que podemos esperar?]. Revista Enfermagem UERJ, 28, e49570. [Acesso em 05/08/2020]. DOl: https://doi.org/10.12957/reuerj.2020.49570. Acesso dia 23 de maio de 2020. Disponível em: https://www.e-publicacoes.uerj.br/index.php/enfermagemuerj/ article/view/49570

3. Freitas, ARA, Napimoga, M, Donalisio, MR Análise da gravidade da pandemia de Covid-19. Epidemiologia e Serviços de Saúde [online]. v. 29, n. 2 [Acessado 23 maio de 2020], e2020119. Disponivel em: <https://doi.org/10.5123/S167949742020000200008>. ISSN 2237-9622. https://doi. org/10.5123/S1679-49742020000200008.

4. Ministério da Saúde. Brasil confirma primeiro caso da doença. 0 Ministério; 2020. Acesso Em 23 de maio de 2020. Disponível em: https://www.saude.gov.br/noticias/agencia-saude/46435-brasil-confirma-primeiro-caso-de-novo-coronavirus .

5. Ministério da Saúde. Notificação de casos pelo novo coronavírus (COVID-2019). Plataforma Integrada de Vigilância em Saúde, 2020. [Acesso em 04/06/2020].

Disponivel em: http://plataforma.saude.gov.br/novocoronavirus

6. Brasil. Lei n. 7.498/86. Dispõe sobre a regulamentação do ex- ercício da Enfermagem e dá outras providências. Brasília; 1986. Acesso em 24 de outubro de 2020. Disponivel em: http://www. planalto.gov.br/CCIVIL/LEIS/L7498.htm

7. Pinto, JB. Ação educativa através de um método participativo no setor saúde. In: Encontro de Experiências de Educação e Saúde da região Nordeste, Natal, 1982. Ação Participativa: metodologia. Anais. Brasília: Centro de Documentação do Ministério da Saúde, 1987. p. 15 - 19. [Série F: Educação e Saúde,4]. [Acesso em 20/05/2020]. Disponível em: https://pesquisa.bvsalud. org/portal/resource/pt/biblio-1094832

8. Falkenberg, MB et al. Educação em saúde e educação na saúde: conceitos e implicações para a saúde coletiva. Ciência \& Saúde Coletiva [online]. 2014, v. 19, n. 03 [Acesso 15 maio 2020], pp. 847-852. Disponivel em: <https://doi.org/10.1590/141381232014193.01572013>. ISSN 1678-4561.

9. Silva, FP. Brasil. Efeitos da apresentação de material educativo para pacientes com diabetes mellitus tipo 2, sobre conhecimento da enfermidade e a adesão ao tratamento. Abr. - 2009. [Acesso em 23/07/2020].. Disponivel em: https://repositorio.unb.br/ handle/10482/4050.

10. Gil, AC. Como elaborar projetos de pesquisa. 5a ed. São Paulo: Atlas, 2010.

11. Santos CMC, Pimenta CAM, Nobre MRC. A estratégia PICO para a construção da pergunta de pesquisa e busca de evidências. Rev. Latino-Am. Enfermagem [Internet]. 2007 June [Acesso em 15/05/2020].; $15(3$ ): 508-511. Disponivel em: http://www. scielo.br/scielo.php?script=sci_arttext\&pid=S0104-

12. FreitasFV, Rezende FLA. Modelos de comunicação e uso de im- 


\section{REFERÊNCIAS}

pressos na educação em saúde: uma pesquisa bibliográfica. Interface (Botucatu) [Internet]. 2011 Mar; [Acesso em 05/08/2020]. 15(36): 243-256. Disponivel em: http://www.scielo.br/scielo. php?script=sci_arttext\&pid=S1414-32832011000100019\&Ing=en. Epub Dec 17, 2010. http://dx.doi.org/10.1590/S141432832010005000044

13. Paula MANR; Carvalho AP, 0 gênero textual folder a serviço da educaçãoambiental. http://dx.doi.org/10.5902/2236117013794 Revista do Centro do Ciências Naturais e Exatas - UFSM, Santa Maria Revista Eletrônica em Gestão, Educação e Tecnologia Ambiental - REGET e-ISSN 22361170 - V. 18 n. 2 Mai-ago. 2014, p.982-989. [Acesso em 15/09/2020]. Disponivel em: 231163779.pdf (core.ac.uk)

14. Sibellino LO; Freire RM et al Atuação discente na produção de folders e panfletos sobre arboviroses como materiais educativos. Rev. Bra. Edu. Saúde, v. 9, n.3, p. 16-23, jul-set, 2019. [Acesso em 06/08/2020]. Disponível em: 6468-33865-2-PB.pdf

15. Ministério da Saúde. Corona vírus Brasil. Dados epidemiológicos. DF: O Ministério; 2020. Acesso em: 23 de maio de 2020. Disponivel em: https://covid.saude.gov.br/

16. David, HMSL, Bonetti, OP, Silva, MRF. A Enfermagem brasileira e a democratização da saúde: notas sobre a Política Nacional de Educação Popular em Saúde. Rev. Bras. Enferm. [Internet]. 2012 [Acesso em 07/04/2020]. 65(1): 179-185. Disponivel em: http://www.scielo.br/scielo.php?script=sci_arttext\&pid=S0034-71672012000100026\&lng=en. http://dx.doi. org/10.1590/S0034-71672012000100026.

17. Menezes GAC, Rosa RSD. Práticas educativas em saúde: a enfermagem revendo conceitos na promoção do autocuidado. REME - Rev Min Enferm. 2004, [Acesso em 23/08/2020].; 8(2):337-40. Disponivel em: http://www.reme.org.br/artigo/detalhes/747

18. Ervera, DPP; Parreira, BDM; Goulart, BF. Educação em saúde: percepção dos enfermeiros da atenção básica em Uberaba (MG). Ciênc. Saúde Coletiva [Internet]. 2011 [Acesso em 20/05/2020].; 16(Suppl 1 ): 1547-1554. Available from: http://www.scielo.br/scielo.php?script=sci_arttext\&pid=S1413-81232011000700090\&Ing=en. http://dx.doi. org/10.1590/S1413-81232011000700090.

19. Pereira SW. Abordagens metodológicas utilizadas em intervenções educativas voltadas a indivíduos com diabetes mellitus Enferm. actual Costa Rica (Online) ; (38): 260-271, jan.-jun. 2020. LILACS, BDENF - Enfermagem. ID: biblio-1090100. [Acesso em 16/05/2020]. Disponivel em: https://pesquisa.bvsalud.org/portal/resource/pt/biblio-1090100

20. Roecker S; Nunes EFP, Marcon SS. O trabalho educativo do enfermeiro na estratégia saúde da família. Texto Contexto Enferm, Florianópolis, 2013 Jan-Mar; 22(1): 157-65. [Acesso em 16/05/2020]. Disponível em: pt_19.pdf (scielo.br)

21. Brasil. Plano de Contingência para Epidemia da Doença pelo Corona vírus 2019 (COVID-19). Secretária de Estado de Saúde, Distrito Federal, 2020. Acesso em: 20 de abril de 2020. Dis- ponivel em: https://pesquisa.bvsalud.org/brasil/resource/pt/ biblio-1095780?view=mobile.

22. Brasil. Distrito Federal, Diário Oficial da União, portaria $n^{\circ}$ 2.789 de 14 de outubro de 2020 . Dispõe sobre as medidas de proteção para enfrentamento da emergência de saúde pública de importância internacional decorrente do Coronavírus (Covid-19), no âmbito das unidades do Ministério da Saúde no Distrito Federal e nos Estados. Acesso em 14/10/2020. Disponível em: Orientações para retomada com segurança (saude.gov.br)

23. Nascimento, EA et al. Panfletos educativos sobre saúde: um estudo de recepção. Rev. Esc. Enferm. USP vol.49 no.3 São Paulo Junho 2015. [Acesso em 05/08/2020]. Disponível em: https:// doi.org/10.1590/S0080-623420150000300011

24. Brasil, Conselho Federal de Enfermagem, Conselho Regional de Enfermagem. COVID-19 Orientações sobre a colocação e retirada dos equipamentos de proteção individual (EPIs). 18p. Brasília; 2020. [Acesso em 05/05/2020]. Disponivel em: https:// pesquisa.bvsalud.org/brasil/resource/pt/biblio1095780?viee=mobile.

25. O Ministério da Saúde. Cartilha, corona vírus e informações. Distrito Federal, 2020. Acesso em: 24 de abril de 2020. Disponivel em: https://www.saude.gov.br/images/pdf/2020/ April/07/Cartilha-Coronavirus-Informacoes-.pdf.

26. Brasil. Ministério da Saúde. Caderno de Educação Popular em Saúde. DF: O Ministério; 2007. Acesso em 04/05/2020. Disponivel em contras-rosto-expediente:contras-rosto-expediente.qxd.qxd (saude.gov.br)

27. Cardoso, J. Entre campanhas, notícias e direitos: os laços entre comunicação e SUS numa trajetória de pesquisa. Revista Eletrônica de Comunicação, Informação e Inovação em Saúde, 14(4). [Acesso em 05/08/2020]. Disponivel em: doi:https://doi. org/10.29397/reciis.v14i4.2263

28. Lana, RM et al. Emergência do novo coronavírus (SARSCoV-2) e o papel de uma vigilância nacional em saúde oportuna e efetiva. Cadernos de Saúde Pública [online]. v. 36, n. 3. [Acesso em 28/06/2020]. Disponivel em: <https://doi. org/10.1590/0102-311X00019620>. ISSN 1678-4464. https:// doi.org/10.1590/0102-311X00019620

29. Lima, LMAO. Informações sobre o novo coronavírus (COVID-19). Radiol Bras [Internet]. [Acesso em 19/04/2020].; 53 (2): V-VI. [Acesso em 05/08/2020]. Disponivel em: http://www.scielo.br/scielo.php?script=sci_arttext\&pid=S0100-39842020000200001\&lng=pt. https://doi. org/10.1590/0100-3984.2020.53.2e1.

30. Belasco AGS, Fonseca CD. Coronavírus 2020. Rev. Bras. A enferm. [Internet]. [Acesso em 17/08/2020].; 73(2): 2020n2. Disponivel em: http://www.scielo.br/scielo.php?script=sci_arttext\&pid=S0034-71672020000200100\&Ing=en. Epub Mar 27, 2020. https://doi.org/10.1590/0034-7167-2020730201

31. Capalbo C. Fenomenologia e Ciências Humanas. São Paulo: Ideias e Letras; 2012. 